\title{
Hippocampal changes produced by overexpression of the human CHRNA5/A3/B4 gene cluster may underlie cognitive deficits rescued by nicotine in transgenic mice
}

\author{
Susanna Molas ${ }^{1,2,3}$, Thomas Gener ${ }^{1,2,3}$, Jofre Güell ${ }^{1}$, Mairena Martín ${ }^{4,5}$, Inmaculada Ballesteros-Yáñez ${ }^{4}$,
} Maria V Sanchez-Vives ${ }^{6,7}$ and Mara Dierssen ${ }^{1,2,3^{*}}$

\begin{abstract}
Addiction involves long-lasting maladaptive changes including development of disruptive drug-stimuli associations. Nicotine-induced neuroplasticity underlies the development of tobacco addiction but also, in regions such as the hippocampus, the ability of this drug to enhance cognitive capabilities. Here, we propose that the genetic locus of susceptibility to nicotine addiction, the CHRNA5/A3/B4 gene cluster, encoding the $\mathrm{a} 5$, $\mathrm{a} 3$ and $\beta 4$ subunits of the nicotinic acetylcholine receptors (nAChRs), may influence nicotine-induced neuroadaptations. We have used transgenic mice overexpressing the human cluster (TgCHRNA5/A3/B4) to investigate hippocampal structure and function in genetically susceptible individuals. TgCHRNA5/A3/B4 mice presented a marked reduction in the dendrite complexity of CA1 hippocampal pyramidal neurons along with an increased dendritic spine density. In addition, TgCHRNA5/A3/B4 exhibited increased VGLUT1NGAT ratio in the CA1 region, suggesting an excitatory/inhibitory imbalance. These hippocampal alterations were accompanied by a significant impairment in short-term novelty recognition memory. Interestingly, chronic infusion of nicotine $(3.25 \mathrm{mg} / \mathrm{kg} / \mathrm{d}$ for $7 \mathrm{~d})$ was able to rescue the reduced dendritic complexity, the excitatory/inhibitory imbalance and the cognitive impairment in TgCHRNA5/A3/B4. Our results suggest that chronic nicotine treatment may represent a compensatory strategy in individuals with altered expression of the CHRNA5/A3/B4 region.
\end{abstract}

Keywords: CHRNA5/A3/B4, Cognition, Hippocampus, Neuroplasticity, Nicotine, Tobacco addiction

\section{Introduction}

It is now generally accepted that addiction represents a neuropathology of learning and memory [1]. Drugs of abuse, including nicotine, induce neuroplasticity in areas involved in cognitive function, such as the hippocampus, a neuroadaptation assumed to contribute to the development of addiction by favoring associative memories [2-6]. These neuroadaptations occur at the level of neuronal structure and synaptic strength and also underlie the effects of the drug on cognitive performance [7-11].

\footnotetext{
* Correspondence: mara.dierssen@crg.es

${ }^{1}$ Cellular and Systems Neurobiology, Systems Biology Program, Centre for Genomic Regulation (CRG), Barcelona Biomedical Research Park (PRBB) building, Room 522.04; C/ Dr. Aiguader 88, E-08003 Barcelona, Spain

${ }^{2}$ Universitat Pompeu Fabra (UPF), E-08003 Barcelona, Spain

Full list of author information is available at the end of the article
}

In the case of nicotine addiction, two of the most common withdrawal symptoms are both changes in affection and cognition, which, during periods of abstinence from smoking, predict relapse [12]. Nicotinic acetylcholine receptors (nAChRs) are the main targets of nicotine. They also play a significant role in cognition and its disruption has been demonstrated in numerous psychiatric and neurological disorders that present cognitive alterations, including schizophrenia [13], attention deficit hyperactivity disorder [14] or Alzheimer's disease [15]. All these neuronal disorders exhibit defects in the dendritic architecture of hippocampal pyramidal neurons and excitatory/inhibitory synaptic connectivity in the hippocampus, which are considered to play critical roles in cognitive function and dysfunction [16-18]. Hence, understanding the genetic influences on the effects of nicotine 
on cognition should contribute to the advancement of nicotine addiction treatment, although this area of research is relatively new.

However, not all individuals develop addiction to tobacco $[19,20]$, nor the effects of nicotine on cognitive function are equal across human populations [21,22], suggesting that changes induced by nicotine consumption may be different in susceptible individuals. The CHRNA5/ $A 3 / B 4$ gene cluster encoding the $\alpha 5, \alpha 3$ and $\beta 4$ subunits of the nAChRs [23] is the major genomic locus associated with nicotine dependence in humans $[24,25]$. This region has also been linked to reduced levels of performance in cognitive domains such as response inhibition, attention and discriminative abilities [26,27]. Interestingly, Zhang et al. [28] demonstrated that current smoking corrects the increased perseverative errors and responses associated with this cluster in a cognitive flexibility test battery. These findings in human individuals support the view that some nicotine-dependent subjects may become addicted as a means of self-medication [29], explaining the fact that tobacco use is more prevalent and intense in human populations that manifest cognitive alterations [22].

We here tested the hypothesis that the CHRNA5/A3/B4 cluster could modify the development of tobacco addiction and cognitive function by influencing neuroplasticity in the hippocampus, one of the few brain regions that expresses the $\alpha 5, \alpha 3$ and $\beta 4 \mathrm{nAChR}$ subunits [30-36]. To this end, we used a BAC transgenic mouse model overexpressing the human CHRNA5/A3/B4 gene cluster (TgCHRNA5/A3/ $B 4)$, which exhibit increased sensitivity to the pharmacological effects of nicotine [37], along with increased binding sites for nicotinic agonists in hippocampal membrane preparations [38] and hippocampal slices, particularly in the CA1 region [37]. We provide evidence that the overexpression of the $C H R N A 5 / A 3 / B 4$ region has an effect on the dendritic architecture of hippocampal pyramidal neurons, on the excitatory/inhibitory balance and on recognition memory. These structural and functional alterations in transgenic mice are rescued upon chronic nicotine administration.

\section{Materials and methods}

\section{Animals}

Transgenic mice overexpressing the human gene cluster CHRNA5/A3/B4 (TgCHRNA5/A3/B4) [37] were obtained from crosses of $\mathrm{TgCHRNA5/A3/B4}$ males and B6/SJL-F1J females. Two transgenic TgCHRNA5/A3/B4 lines (L30 and L22; see our previous work [37]) were generated and showed no differences in their phenotype, excluding the possibility that the phenotypic profile of $\mathrm{TgCHRNA5/A3/}$ $B 4$ and their response to nicotine might be attributed to the transgene insertion sites. In all experiments wild type (WT) littermates served as controls. Adult male mice (23 months of age) were group housed with 3-5 animals per cage under a $12 \mathrm{~h}$ light/dark schedule, in controlled environmental conditions of humidity (50-70\%) and temperature $\left(21 \pm 1^{\circ} \mathrm{C}\right)$, with food and water supplied ad libitum. All experimental procedures were approved by the local ethical committee (CEEA - PRBB), and met the guidelines of the local (Catalan law 5/1995 and Decrees 214/97, 32/2007) the European regulations (EU directives 86/609 and 2001-486) and the Standards for Use of Laboratory Animals A5388-01 (NIH).

\section{Drug administration}

(-)-Nicotine hydrogen tartrate was purchased from Sigma-Aldrich (St. Louis, MO). For the in vivo studies, animals were subcutaneously implanted with Alzet osmotic minipumps (Model 2001) (Alzet, Cupertio, CA) under $\mathrm{O}_{2}-$ isofluorane mixture anesthesia. Each minipump contained either saline $(0.9 \% \mathrm{NaCl})$ or nicotine solutions $(3.25 \mathrm{mg} / \mathrm{Kg} / \mathrm{d}$, free base) and delivered a constant subcutaneous flow in a rate of $1 \mu \mathrm{l} / 1 \mathrm{~h}$. The concentration of nicotine was adjusted to compensate for body weight differences among subjects. This nicotine administration regime gives rise to sustained plasma nicotine concentrations similar to that reached in heavy smokers [39] and induces physical dependence in mice [40]. For the in vitro studies, (-) - nicotine was dissolved in fresh medium (3.25 $\mu \mathrm{M}$, free base) and hippocampal primary cultures received medium alone or containing nicotine for $48 \mathrm{~h}$.

\section{Histological analysis}

All mice were deeply anesthetized with isofluorane and perfused with $0.1 \mathrm{M}$ phosphate buffer saline (PBS) followed by $4 \%$ paraformaldehyde (PFA, Sigma, St. Louis, MO). Mice were sacrificed on the seventh day after minipump implantation; the brains were removed and sliced at Bregma - 1.34 $\mathrm{mm}$ to $-2.18 \mathrm{~mm}$.

\section{Morphometry of hippocampal pyramidal neurons}

We used intracellular injections of Lucifer yellow ( $L Y$, L0259; Sigma, St. Louis, MO) [41,42]. Briefly, $150 \mu \mathrm{m}$ thick vibratome-sliced sections were prelabeled with 4,6diamidino-2-phenylindole (D9542; Sigma) and neurons from dorsal CA1 hippocampus were injected with $L Y$ by continuous current ( $\mathrm{n}=5-10$ cells/animal; $4-5$ animals/ group from $\geq 3$ experiments). After injecting the neurons, sections were first processed with anti- $L Y$ antibody made in rabbit (1:10 000, Sigma, L9163, in stock solution: $2 \%$ bovine serum albumin [A3425; Sigma], 1\% Triton X-100 [30632; BDH Chemicals, Poole, UK], and 5\% sucrose in PBS) and then with a biotinylated donkey anti-rabbit secondary antibody (1:200 in stock solution; RPN1004; Amersham Pharmacia Biotech, Little Chalfont, UK). Immunolabeled cells were visualized with Alexa Fluor 488-conjugated streptavidin (1:1000 in PBS, Invitrogen). 
Only cells identified as pyramidal neurons and whose entire apical dendrite arbor was completely filled were included in the analysis. Images were acquired at $40 \mathrm{x}$ with a LSM 710 Zeiss confocal microscope equipped with laser excitation at $488 \mathrm{~nm}$ (Carl Zeiss MicroImaging $\mathrm{GmbH}$, Germany) and each image was a $z$ series projection of over 100 stacks, taken at $1 \mu \mathrm{m}$ depth intervals. Individual neuronal apical arbors were three-dimensionally (3D) reconstructed using Neurolucida software (MicroBrightField, Inc., Vermont, USA) and morphometric analysis was performed using Neuroexplorer software (MicroBrightField, Inc., Vermont, USA) [43]. This module opens an image stack of confocal images and allows the measurement of several morphological parameters of dendritic arborisation. The following parameters were analysed: Sholl analysis (branching complexity, measured as the number of dendritic intersections within concentric $10 \mu \mathrm{m}$ radial spheres, calculated as a function of distance from the soma), total number of nodes, total dendritic length, dendritic volume (the volume of a neuron's apical dendritic field calculated as the volume enclosed by a polygon created by joining the most distal points of the dendritic processes, the 3D convex Hull volume) [44].

To further investigate neuronal structure of pyramidal neurons, TgCHRNA5/A3/B4 males were crossed with Thy1-YFP (Yellow Fluorescent Protein) heterozygous females (B6.Cg-Tg (Thy1-YFPH) 2Jrs/J; Jackson Laboratories) and obtained double transgenic mice that expressed YFP sparsely in subsets of pyramidal neurons. Brains were extracted as described before, postfixed with $4 \%$ PFA and cryoprotected with $30 \%$ sucrose. A vibratome (Leica, Wetzlar, Germany) was used to obtain coronal sections (150 $\mu \mathrm{m}$ thick). Fluorescent images were obtained with a SP5 confocal microscope (Leica, Wetzlar, Germany) and analyzed by ImageJ software. The number of basilar (stratum oriens) and apical (stratum radiatum) dendritic structures of CA1 pyramidal neurons was determined within a $50 \times 50 \mu \mathrm{m}^{2}$ area in a single plane images acquired at $40 \times(\mathrm{n}=\geq 100$ images animal; 4-5 animals/ group from $\geq 3$ experiments). The dendritic spine density of CA1 pyramidal neurons was quantified along $30 \mu \mathrm{m}$ length sections of primary and secondary dendrites, at $50 \mu \mathrm{m}$ from the cell soma and, expressed as number of spines per $10 \mu \mathrm{m}(\mathrm{n}=5-10$ cells/animal; 4-5 animals/ group from $\geq 3$ experiments). Spine count was performed on images acquired at $63 \times$ with $2.0 \times$ (optical zoom), generating a stack from $9-10$ images, taken at $0.36 \mu \mathrm{m}$ depth intervals. Dendritic spines were separated on morphological categories as previously described (stubby, mushroom-like, thin or filopodia) [45]. The number of pyramidal cells per CA1 and CA3 areas was quantified on images acquired at $20 \times$ and taken at different $x, y$ and $z$ coordinates to visualize the entire hippocampus. Each image was a $z$ series projection of approximately 10-12 stacks, and taken at $5 \mu \mathrm{m}$ depth intervals.

\section{Immunohistochemistry}

Vesicular glutamate transporter (VGLUT1) and vesicular GABA transporter (VGAT) were used as markers for excitatory and inhibitory synaptic inputs [46]. 40 $\mu \mathrm{m}$ thick coronal sections were obtained from brains extracted as described before, using a cryostat (Leica, Wetzlar, Germany). Samples were permeabilized with 0.1M PBS 0.5\% Triton X-100 (PBST) (Sigma, St. Louis, MO), and blocked in $20 \%$ fetal bovine serum (FBS) PBST, for $1 \mathrm{~h}$ at room temperature (RT). Samples were incubated with the primary antibodies anti-VGLUT1 (mouse, 1:200, Synaptic Systems, Goettingen, Germany) and anti-VGAT (guinea pig, 1:200, Synaptic Systems, Goettingen, Germany), in 5\% FBS PBST, overnight at $4^{\circ} \mathrm{C}$. After washes in PBST, they were incubated with secondary fluorescently labeled antibodies (Alexa ${ }^{\circ}$ Fluor 488 and Alexa ${ }^{\circ}$ Fluor 594, Life Technologies, Grand Island, NY) in 5\% FBS PBST for $1 \mathrm{~h}$, at RT. Images were acquired with SPE Confocal Microscope (Leica, Wetzlar, Germany), connected to the LAS AF software (Leica, Wetzlar, Germany), and analyzed using Image J software. Background was subtracted from negative control values of each sample and the same threshold was applied for each channel. The number of VGLUT1 and VGAT puncta was quantified within a $20 \times 20 \mu^{2}$ region of the CA1 strata oriens and radiatum on single plane images obtained at $63 \times$ with $5.0 \times$ (optical zoom) $(n=\geq 100$ images animal; 4-5 animals/group from $\geq 3$ experiments).

\section{Electrophysiological recordings}

Field excitatory postsynaptic potentials (fEPSPs) were recorded in the stratum radiatum of dorsal hippocampal CA1 region in response to stimulation of the Schaffer collateral (SC) pathway ( $\mathrm{n}=3-5$ recordings/animal; $4-5$ animals/group from $\geq 3$ experiments). Mice were sacrificed by decapitation on the seventh day after minipump implantation, the brain was quickly removed and placed on ice-cold cutting solution (in $\mathrm{mM}$ ): $2.5 \mathrm{KCl} ; 3 \mathrm{MgSO}_{4} ; 1.25$ $\mathrm{NaHPO}_{4} ; 1 \mathrm{CaCl}_{2} ; 26 \mathrm{NaHCO}_{3} ; 10$ sucrose and aerated with $95 \% \mathrm{O}_{2}-5 \% \mathrm{CO}_{2}$ to a final $\mathrm{pH}$ of 7.4. Coronal slices (400 $\mu \mathrm{m}$ thick) were obtained with a vibratome (Leica, Wetzlar, Germany); placed in an interface style recording chamber (Fine Science Tools, Foster City, CA) and bathed in artificial cerebrospinal fluid (ACSF) containing (in $\mathrm{mM}): 124 \mathrm{NaCl} ; 2.5 \mathrm{KCl} ; 1 \mathrm{MgSO}_{4} ; 1.25 \mathrm{NaHPO}_{4} ; 2.5$ $\mathrm{CaCl}_{2} ; 26 \mathrm{NaHCO}_{3}$; and 10 dextrose aerated with 95\% $\mathrm{O}_{2}-5 \% \mathrm{CO}_{2}$ to a final $\mathrm{pH}$ of 7.4. Bath temperature was maintained at $32-34^{\circ} \mathrm{C}$. Unfiltered recordings were obtained by means of ACSF-filled glass electrodes (impedance 1-2 $\mathrm{M} \Omega$ ) through a Neurolog system (Digitimer) amplifier. Electrical stimuli were delivered using a stimulus 
isolator unit in constant current mode (WPI, Sarasota, FL) with a concentric monophasic bipolar electrode (200- $\mu$ m-diameter ultra-small concentric bipolar electrode; Frederick Haer Co., Bowdoinham, ME). Stimulus strength was adjusted to a stimulation intensity that yielded a half-maximal response $(50-150 \mu \mathrm{A})$. For each slice, after establishing a stable response (electrical stimulation at $0.03 \mathrm{~Hz}$ ), paired-pulse facilitation (PPF) was induced by a double-pulse (50 $\mathrm{ms}$ apart) stimulation protocol. PPF is a short-term presynaptic phenomenon that at SC-CA1 synapses it is inversely related to the probability of neurotransmitter release [47]. Long-term potentiation (LTP) was induced by a high frequency stimulation protocol (HFS; $100 \mathrm{~Hz} ; 1 \mathrm{~s}) 20 \mathrm{~min}$ after baseline recording. Responses were recorded for a period of $60 \mathrm{~min}$ (pulse at $0.03 \mathrm{~Hz}$ ) and the magnitude of LTP was measured by averaging the percent increase of the fEPSP slope compared with baseline. Recordings were acquired, digitized, and analyzed using a data acquisition interface and software from Cambridge Electronic Design (Spike2).

\section{Cell culture}

Hippocampal primary cultures were obtained from WT and TgCHRNA5/A3/B4 mice at embryonic day 17.5 - 18.5 ( $\mathrm{n}=4$ independent experiments, 3-4 cultures/condition from $\geq 3$ experiments). Cultures were obtained from individual embryos; no pool of material was mixed. Hippocampi were dissected on ice-cold Dulbecco's Modified Eagle Medium (DMEM) (Life Technologies, Grand Island, NY). Cells were mechanically dissociated, centrifuged and resuspended in $0.5 \mathrm{ml}$ Neurobasal culture medium, supplemented with 2\% B27 factor, 1\% Glutamax, 0.5\% Penicillin/ Streptomycin $\left(\mathrm{NB}^{+++}\right)$and $10 \%$ Inactivated Horse Serum (all reagents were supplied from Life Technologies, Grand Island, NY). Neurons were seed at a density of $5 \times 10^{4}$ cells per well on round glass coverslips and, incubated under culture conditions of $37^{\circ} \mathrm{C}$ and $5 \% \mathrm{CO}_{2} .24 \mathrm{~h}$ after plating, the serum was removed and substituted by $\mathrm{NB}^{+++}$to avoid massive glial proliferation. To analyze the morphology of pyramidal neurons, at day-in-vitro (DIV) 5, cultures were transfected with a plasmid containing enhanced green fluorescent protein (EGFP) driven by the Thy1 promoter (designed and kindly provided by Dr. G. Ramakers, University of Amsterdam), by means of Lipofectamine 2000 (Life Technologies, Grand Island, NY) and following manufacturer instructions. At $D I V 7$, half of the plate received fresh medium alone or containing nicotine for $48 \mathrm{~h}$. All the morphological and biochemical studies were performed in DIV9 cultures fixed in PFA 4\% for 20 min at RT. The dendritic complexity of pyramidal neurons was examined in non-overlapping positive cells expressing EGFP, by means of Sholl analysis $(n=4-5$ cells/culture, 3-4 cultures/condition from $\geq 3$ experiments). Images were acquired with a SP5 Confocal Microscope (Leica, Wetzlar, Germany), connected to the LAS AF software (Leica, Wetzlar, Germany), using a $63 x$ objective generating a $z$ - stack from 7-9 images taken at a $0.5 \mu \mathrm{m}$ depth interval, and at different $x, y$ and $z$ coordinates to visualize the entire neuron. For spine count on transfected neurons, images were acquired at $63 \times$ with $2.0 \times$ (optical zoom), generating a stack from 9-10 images taken at a $0.36 \mu \mathrm{m}$ depth interval. Spines were quantified along $30 \mu \mathrm{m}$ length sections of primary and secondary dendrites at a distance of $50 \mu \mathrm{m}$ from the cell soma, and expressed as number of spines per $10 \mu \mathrm{m}$ of dendrite length ( $\mathrm{n}=4-5$ cells/culture, $3-4$ cultures/condition from $\geq 3$ experiments). To examine glutamatergic and GABAergic inputs in the neuronal cultures, immunofluorescence labeling against VGLUT1 and VGAT markers was performed as describe above. The number of VGLUT1 and VGAT puncta per $10 \mu \mathrm{m}$ of dendrite was determined within a region of $50 \mu \mathrm{m}$ proximal to the cell body of neurons, with aids of Image J software $(n=4-$ 5 cells/culture, $3-4$ cultures/condition from $\geq 3$ experiments). To assess the viability of the cultures at DIV9, neurons were incubated with 3-(4,5-dimethyolthiazol-2yl)-2,5-diphenyltetrazlium bromide (MTT, $500 \mu \mathrm{g} / \mathrm{ml}$, Sigma, St. Louis, MO) in $0.1 \mathrm{M}$ PBS for $30 \mathrm{~min}$, at $37^{\circ} \mathrm{C}$ and, under dark conditions. After incubation, the medium was removed and formazan dye was extracted using 100\% detergent sodium dodecyl sulfate (DMSO, Sigma, St. Louis, $\mathrm{MO})$. The absorbance was determined using a microplate reader at $550 \mathrm{~nm}(\mathrm{n}=4-5$ wells/culture, 3-4 cultures condition from $\geq 3$ experiments).

\section{Behavioral analysis}

Adult male mice were allowed to habituate to the testing room under dim light for at least $30 \mathrm{~min}$. Animals $(\mathrm{n}=$ 10-12 mice/group from $\geq 3$ experiments) were subjected for novel object recognition memory paradigm on the fourth day after minipumps were implanted. Mice that underwent behavioral tests were never used for histological or electrophysiological analysis.

\section{Novel object recognition (NOR)}

The apparatus consisted of a rectangular open-field arena (70 cm long $\times 70 \mathrm{~cm}$ wide $\times 30 \mathrm{~cm}$ high) made of Plexiglas, surrounded by curtains to avoid the influence of external stimuli during the experiment. Animals' behavior was monitored using System Motor Activity Record and Tracking software (SMART, Panlab Harvard Apparatus, Spain). On the first day, mice were habituated to the arena for $10 \mathrm{~min}$. On the second day, mice were presented with two identical objects, for $10 \mathrm{~min}$. Subjects failing to complete a minimum of $20 \mathrm{~s}$ of exploration during the familiarization session were excluded for posterior analysis. In a $1 \mathrm{~h}$ delay (test session), mice were presented with one familiar object and a novel one, for $5 \mathrm{~min}$. The discrimination index was calculated as time exploring the 
novel object - time exploring the familiar object/total time of exploration *100 [48]. Exploratory behavior was defined as the animal directing its nose towards the object at a distance of $<2 \mathrm{~cm}$ and manually registered by the experimenter. Sitting on or resting against the object was not considered as exploration. All the objects used were plastic made and induced similar exploration levels. The arena and objects were deeply cleaned between animals to avoid olfactory cues. Anxiety-like behavior was measured as percentage of time spent in the periphery of the open field.

\section{Statistical analyses}

All data are presented as mean \pm standard error of mean (SEM). Genotype comparison was performed by Student's $\mathrm{T}$ test. Two-way analysis of variance (ANOVA) was used for genotype and treatment analysis. When the interaction of genotype $\mathrm{x}$ treatment was significant a Bonferroni post hoc test was used as a correction between pair wise comparisons. Otherwise, the significant effect of genotype or treatment was taken into consideration. Repeated measure ANOVA was used for the Sholl analysis. All statistical analyses were performed using Statistical Package for the Social Sciences (SPSS) software (version 19.0).

\section{Results}

CHRNA5/A3/B4 overexpression leads to a reduced dendritic complexity in CA1 hippocampal pyramidal neurons that is rescued by nicotine treatment

Using Lucifer Yellow (LY) injections and neuronal reconstruction techniques, we detected a reduction in the complexity of the apical dendritic tree in $\operatorname{TgCHRNA5/A3/B4}$ CA1 pyramidal neurons, compared to WT $(p=0.019$, Figure 1a-b, Sholl analysis), with decreased number of nodes $(p<0.001$, Additional file 1: Figure S1a). This decrease of branching complexity in transgenic neurons was found only in the proximal region of the apical dendrite, which corresponds to the portion of dendrite mainly receiving excitatory input from CA3 connections, but not in the distal part receiving input from the temporoammonic pathway [49]. Transgenic CA1 pyramidal neurons presented reduced total dendrite length $(p=0.014)$ and total dendrite volume ( $p=0.016$, Additional file 1: Figure S1b-c).

We next investigated if a chronic nicotine treatment in the adult brain affects the dendritic complexity of CA1 pyramidal neurons. To address this question, we used transgenic animals expressing YFP in pyramidal neurons (Thy1-YFP-WT and Thy1-YFP-TgCHRNA5/A3/B4 mice) implanted with saline or nicotine $(3.25 \mathrm{mg} / \mathrm{Kg} / \mathrm{d})$ for $7 \mathrm{~d}$. In saline-treated Thy1-YFP $\mathrm{TgCHRNA5/A3/B4}$ mice we again observed a significant reduction in the number of proximal apical dendrites $(p<0.001)$ and in the proximal portions of basal dendrites $(p<0.001)$ (Figure 1c-d). Chronic nicotine treatment in Thy-YFP-TgCHRNA5/A3/B4 mice rescued this phenotype and increased the number of basal $(p=0.007)$ and apical dendrites $(p<0.001)$ (Figure 1c-d), but reduced both the number of basal $(p<0.001)$ and apical dendrites $(p<0.001)$ in Thy-YFP-WT mice (Figure 1c-d). No differences in the number of pyramidal cell somas per area in the CA1 stratum pyramidale layer were detected between genotypes or treatment groups (Additional file 2: Figure S2a).

\section{Dendritic spine density in CA1 pyramidal neurons increases in WT and TgCHRNA5/A3/B4 mice upon chronic nicotine treatment}

Thy1-YFP-WT and TgCHRNA5/A3/B4 mice treated with either saline or nicotine $(3.25 \mathrm{mg} / \mathrm{Kg} / \mathrm{d}$ for $7 \mathrm{~d})$ were used to examine whether the altered dendritic branching in CA1 pyramidal neurons was accompanied with changes in dendritic spines. Basal dendrites from transgenic neurons did not show differences in total dendritic spines as compared to WT (Figure 1e-f). Nevertheless, they presented an increase in the proportion of stubby spines $(p<0.001)$ along with a non-significant reduction of thin spines (Table 1). In contrast, apical dendrites of Thy1-YFP-TgCHRNA5/A3/B4 pyramidal neurons presented increased density of total dendritic spines, as compared to WT $(p<0.001$, Figure 1e-f). Morphological analysis of spines indicated that, similar to the spines of basal dendrites, this increase was mainly due to increased density of stubby spines $(p=0.039)$ but also of mushroom-like $(p=0.01)$ (Table 1$)$.

Chronic nicotine treatment increased the density of mushroom-like spines on apical dendrites $(p=0.05$, Table 1), without changing the total dendritic spine density, in both Thy1-YFP-WT and Thy1-YFP-TgCHRN$A 5 / A 3 / B 4$ mice (Figure 1e-f). However, nicotine did not affect spine densities in CA1 pyramidal basal dendritic tree.

\section{Reduced excitatory and inhibitory synaptic inputs in the CA1 region of TgCHRNA5/A3/B4 mice are normalized upon chronic nicotine administration}

In the mature brain, most glutamatergic synapses occur at dendritic spines $[45,50]$. Thus, the differences observed in dendritic spines might be associated with changes in the density of excitatory synaptic inputs in the CA1 region. To explore this possibility, we immunostained hippocampal slices from saline or nicotine treated WT and TgCHRNA5/A3/B4 mice using VGLUT1, a commonly used neuronal marker for presynaptic glutamatergic synapses in the mouse hippocampus [51].

$\operatorname{TgCHRNA5/A3/B4}$ exhibited decreased VGLUT1 puncta in strata radiatum $(p<0.001)$ and oriens $(p<$ 0.001 ) (Figure 2a-b) that was restored to control values upon chronic nicotine administration $(3.25 \mathrm{mg} /$ $\mathrm{Kg} / \mathrm{d}$ for $7 \mathrm{~d}$ ), being the restoration more pronounced 
a

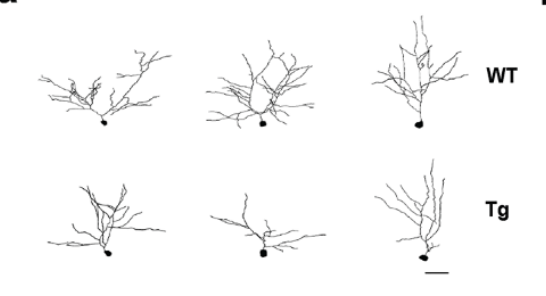

C
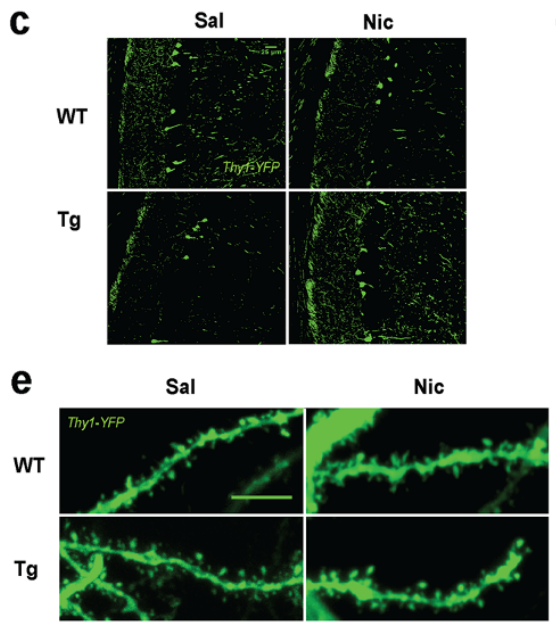

b

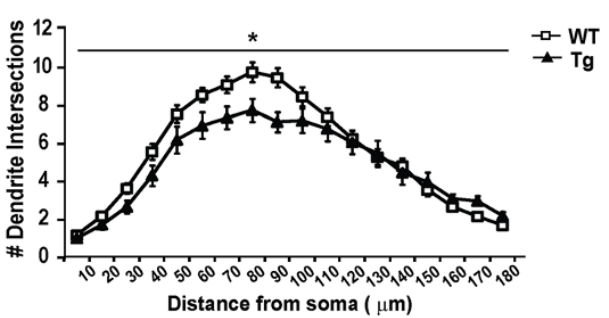

d
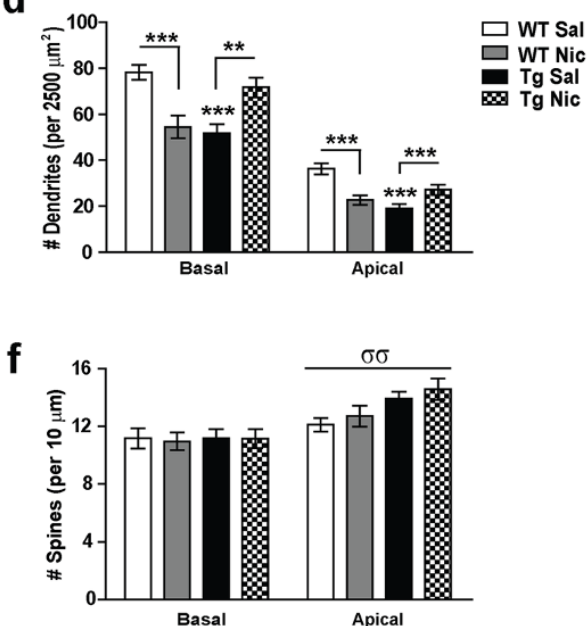

Figure 1 CA1 pyramidal neurons structure in mice overexpressing the CHRNA5/A3/B4 region and upon chronic nicotine treatment. (a) Representative reconstructions of the apical dendritic tree of Lucifer Yellow transfected wild type (WT, upper panel) and TgCHRNA5/A3/B4 neurons ( $(\mathrm{g}$, lower panel), Scale bar $25 \mathrm{\mu m}$. (b) Sholl analysis indicated that transgenic neurons showed reduced number of dendritic intersections compared to WT, particularly at 50 to $150 \mu \mathrm{m}$ from the cell soma ( $n=5-10$ cells/animal; 4-5 animals/group from $\geq 3$ experiments). (c) Representative confocal images of the CA1 region in Thy 1-Yellow Fluorescent Protein (YFP) - WT and Tg mice that received either saline (Sal) or nicotine (Nic, $3.25 \mathrm{mg} / \mathrm{Kg} / \mathrm{d}$ ) for $7 \mathrm{~d}$, Scale bar $25 \mu \mathrm{m}$. (d) Quantification of the number of apical and basal dendritic structures in $50 \times 50 \mu \mathrm{m}^{2}$ area revealed significant reductions in Sal-treated Thy 1-YFP-Tg mice, compared to Sal-treated Thy1-YFP-WT mice. Chronic administration of nicotine restored the dendritic deficit in Thy 1-YFPTg mice but instead the same treatment reduced the number of dendritic structures in Thy1-YFP-WT mice ( $n=\geq 100$ images animal; 4-5 animals/group from $\geq 3$ experiments). (e) Representative photomicrograph illustrating dendritic spines on apical dendrites in CA1 pyramidal neurons from saline and nicotine treated Thy 1-YFP-WT and Tg mice, Scale bar $10 \mu \mathrm{m}$. (f) Quantification of spines per $10 \mu \mathrm{m}$ of dendrite length indicated that apical but not basal dendrites from saline- and nicotine-treated Thy 1-YFP-Tg mice presented increased spines as compared to Thy1-YFP-WT ( $\mathrm{n}=5-10$ cells/animal; 4-5 animals/group from $\geq 3$ experiments). ${ }^{*} p \leq 0.05,{ }^{* *} p \leq 0.01,{ }^{* * *} p \leq 0.001$; Two-way ANOVA genotype effect $\sigma \sigma p \leq 0.01$.

in stratum oriens $(p=0.003)$ than stratum radiatum (Figure 2a-b). In contrast, the same treatment had opposite effects in WT animals, leading to a loss of glutamatergic inputs in the CA1 region (stratum radiatum $p<0.001$; stratum oriens $p<0.001$, Figure $2 \mathrm{a}-\mathrm{b})$.

When examining the density of inhibitory synapses (VGAT puncta), we found similar results, since TgCHRNA5/
A3/B4 showed significantly reduced GABAergic inputs (stratum radiatum $p<0.001$, stratum oriens $p<0.001$, Figure 2c-d). However, the reduction of VGAT exceeded the reductions of VGLUT1 puncta and thus, the ratio of glutamatergic vs. GABAergic input was increased in the CA1

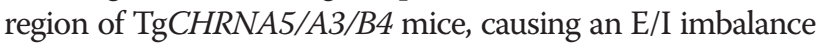
(stratum radiatum $p=0.004$, stratum oriens $p=0.007$,

Table 1 Effects of nicotine on dendritic spines in CA1 pyramidal neurons from adult mice

\begin{tabular}{|c|c|c|c|c|c|c|}
\hline \multirow[b]{2}{*}{ Spines per $10 \mu \mathrm{m}$} & \multicolumn{3}{|c|}{ Apical dendrites } & \multicolumn{3}{|c|}{ Basal dendrites } \\
\hline & Stubby & Mushroom-like & Thin & Stubby & Mushroom-like & Thin \\
\hline WT Sal & $0.90 \pm 0.12$ & $10.94 \pm 0.45$ & $0.27 \pm 0.08$ & $0.84 \pm 0.09$ & $10.30 \pm 0.65$ & $0.03 \pm 0.02$ \\
\hline WT Nic & $0.79 \pm 0.17$ & $11.83 \pm 0.65^{\omega}$ & $0.08 \pm 0.06$ & $0.86 \pm 0.12$ & $10.10 \pm 0.58$ & $0.00 \pm 0.00$ \\
\hline Tg Sal & $1.50 \pm 0.23^{\circ}$ & $12.20 \pm 0.39^{\circ}$ & $0.23 \pm 0.10$ & $1.16 \pm 0.11^{\sigma}$ & $10.01 \pm 0.62$ & $0.01 \pm 0.01$ \\
\hline $\operatorname{Tg} \mathrm{Nic}$ & $0.96 \pm 0.15^{\sigma}$ & $13.51 \pm 0.70^{\sigma, \omega}$ & $0.11 \pm 0.06$ & $1.40 \pm 0.13^{\sigma}$ & $9.74 \pm 0.61$ & $0.00 \pm 0.00$ \\
\hline
\end{tabular}

Number of spines per $10 \mu \mathrm{m}$ of dendrite length, in apical and basal dendrites of CA1 pyramidal neurons from Thy1-YFP-wild type (WT) and Thy1-YFP-TgCHRNA5/ A3/B4 (Tg). Mice were implanted with osmotic minipumps delivering either saline (Sal) or nicotine ( $\mathrm{Nic}, 3.25 \mathrm{mg} / \mathrm{Kg} / \mathrm{d}$ ) for $7 \mathrm{~d}$

( $n=5-10$ cells/animal; 4-5 animals/group from $\geq 3$ experiments). Two-way ANOVA genotype effect ${ }^{\sigma} p \leq 0.05$, treatment effect ${ }^{\omega} p \leq 0.05$. 

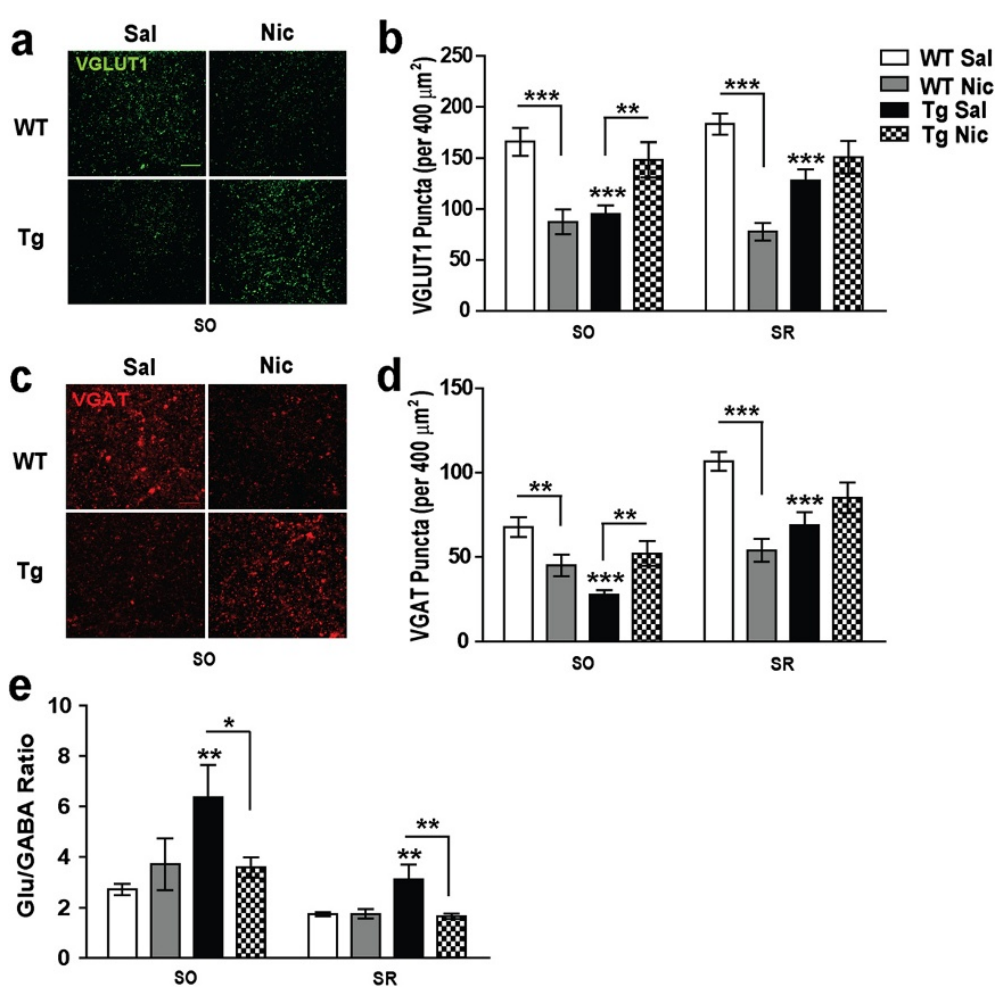

Figure 2 Glutamatergic and GABAergic puncta and their ratio in the hippocampal CA1 region. (a) Representative confocal images of VGLUT1 immunostaining in the stratum oriens (SO) of wild type (WT) and TgCHRNA5/A3/B4 (Tg) mice that received either saline (Sal) or nicotine (Nic, $3.25 \mathrm{mg} / \mathrm{Kg} / \mathrm{d}$ ) for $7 \mathrm{~d}$, Scale bar 5 m. (b) Quantification of VGLUT1 puncta showing that Tg mice presented reduced glutamatergic puncta in SO and stratum radiatum (SR), as compared to their WT littermates. Chronic infusion of nicotine rescued the reduced density of VGLUT1 puncta in the CA1 SO of Tg mice, but caused opposite effects in WT, leading to a significant decrease both in SO and SR. (c) Representative confocal images of VGAT immunostaining in the SO of mice with the conditions indicated, Scale bar $5 \mu \mathrm{m}$. (d) Quantification of VGAT puncta showing reduced GABAergic input in SO and SR of Tg mice, compared to WT. Chronic nicotine increased VGAT puncta in SO in Tg. In contrast, the same treatment reduced VGAT puncta in SO and SR in WT mice. (e) The glutamatergic (Glu)/GABAergic ratio in CA1 SO and SR regions was increased in Tg mice, as compared to WT. Chronic nicotine treatment rescued the increased Glut/GABA ratio in Tg, with no effect in WT ( $n=\geq 100$ images animal; $4-5$ animals/group from $\geq 3$ experiments). ${ }^{*} p \leq 0.05,{ }^{* *} p \leq 0.01,{ }^{* * *} p \leq 0.001$.

Figure 2e). In all groups of mice the density of GABAergic input was higher in stratum radiatum than in stratum oriens (Figure 2c), reflecting a greater inhibitory regulation in this region, as previously described [52]. Chronic nicotine normalized the density of GABAergic inputs in TgCHRNA5/ $A 3 / B 4 \quad(p=0.002$, Figure 2c-d $)$ and compensated for their $\mathrm{E} / \mathrm{I}$ imbalance (stratum radiatum $p=0.003$; stratum oriens $p=0.039$, Figure 2e). Conversely, chronic nicotine reduced GABAergic inputs in WT mice (stratum radiatum $p<0.001$; stratum oriens $p=0.006$, Figure $2 \mathrm{c}-\mathrm{d}$ ), but without modifying their E/I balance (Figure 2e). The treatment did not modify the density of CA3 pyramidal neurons neither in WT nor in TgCHRNA5/A3/B4 mice, the major excitatory inputs in the CA1 region (Additional file 2: Figure S2b).

\section{Chronic nicotine enhances HFS-induced LTP at SC-CA1 connections in WT and TgCHRNA5/A3/B4 mice}

We further interrogated whether differences in excitatory and inhibitory synapses described above could underlie changes in synaptic strength, such as LTP responses, considered the cellular substrate of memory function [53]. To this aim, we recorded fEPSPs in the CA1 stratum radiatum region evoked by HFS $(100 \mathrm{~Hz}, 1 \mathrm{~s})$ applied to SC afferents. Recordings were performed in slices from WT and $\operatorname{TgCHRNA5/A3/B4}$ animals treated with saline or chronic nicotine $(3.25 \mathrm{mg} / \mathrm{Kg} / \mathrm{d}$ for $7 \mathrm{~d})$. The results showed that HFS stimulation to SC amplified the degree of CA1 synaptic potentiation along the $60 \mathrm{~min}$ of recordings, similarly in slices from saline-treated TgCHRNA5/A3/B4 and WT mice (Figure 3a-b). Additionally, using paired pulse facilitation (50 ms apart) no differences were observed between genotypes in release probability (Figure 3c).

Chronic nicotine administration reduced the threshold for LTP induction at SC-CA1 pathway (Figure 3a-b). Slices from mice that received the drug treatment elicited increased synaptic potentiation immediately upon stimulation (at 15 min post HFS, $p=0.002$, Figure $3 \mathrm{~b}$ ) that was maintained for more than $45 \mathrm{~min}(p=0.009$, Figure $3 \mathrm{~b})$. Noticeably, the effects of nicotine on LTP induction were 

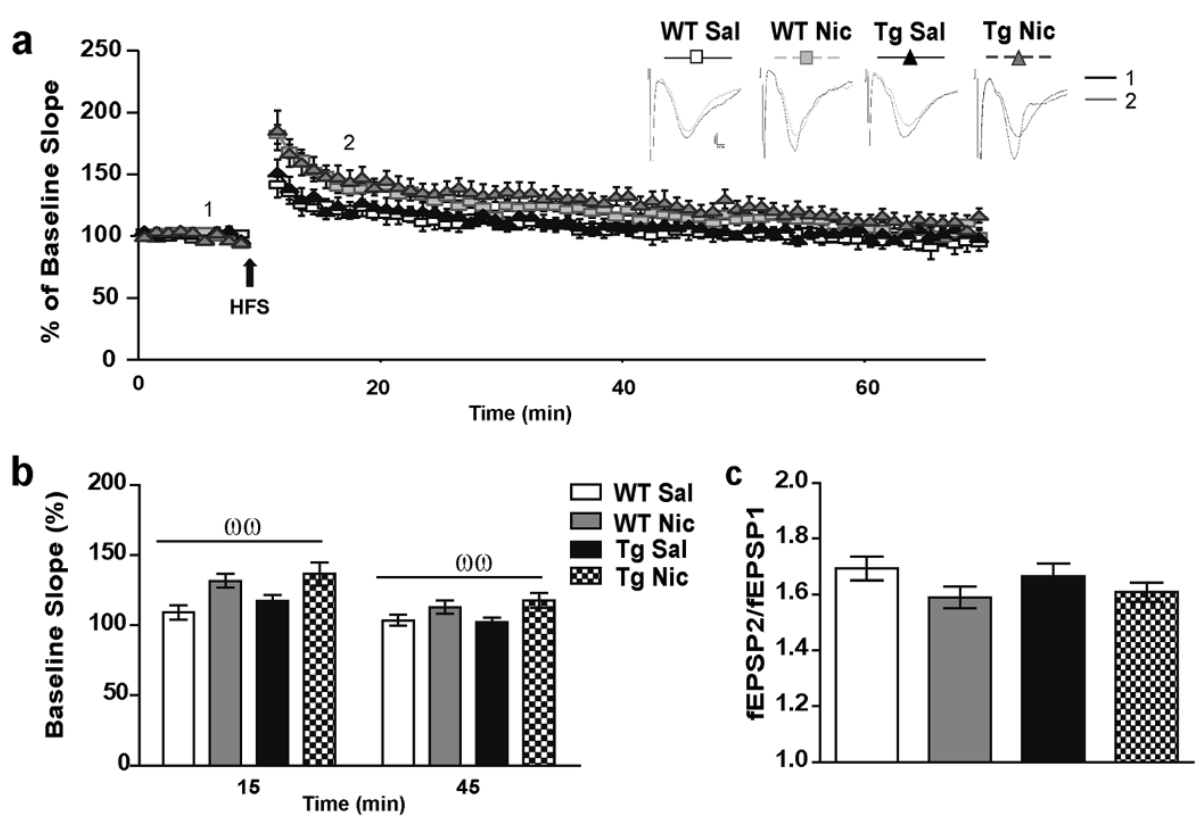

Figure 3 Electrically induced synaptic plasticity of Shaffer collateral-CA1 pathway. (a) High frequency stimulation (HFS; 100Hz, 1s) induced synaptic potentiation at Schaffer Collateral (SC)-CA1 synapses similarly in slices from saline (Sal)-treated wild type (WT) and TgCHRNA5/A3/B4 (Tg) mice. Chronic nicotine (Nic, $3.25 \mathrm{mg} / \mathrm{Kg} / \mathrm{d}$ ) administration for $7 \mathrm{~d}$ enhanced synaptic potentiation both in WT and Tg mice. Upper panel: representative field excitatory postsynaptic potentials (fEPSPS) in response to one stimulation in the CA1 stratum radiatum before (1) and 15 min after (2) applying HFS (arrow), Scale bar $0.5 \mathrm{mV}$ and $1 \mathrm{~ms}$. Lower panel: slopes of the fEPSPs normalized to those obtained before applying HFS (\%). (b) Mean values of fEPSPs potentiation at 15 and $45 \mathrm{~min}$ after HFS. (c) The paired pulse ratio (fEPSP2/fEPSP1) with an inter-pulse interval of 50 ms (response average of 5 paired pulses; time interval $1 \mathrm{~s}$ ) was similar among slices from the different experimental conditions ( $n=3-5$ recordings/animal; $4-5$ animals/group from $\geq 3$ experiments). Two-way ANOVA treatment effect $\omega \omega p \leq 0.01$.

similar between genotypes. Moreover, chronic nicotine had no significant effect on paired pulse facilitation (Figure 3c).

Reduced dendrite arborization of cultured TgCHRNA5/A3/B4 hippocampal neurons is rescued by nicotine

The morphological features of pyramidal neurons in the brain are influenced by the anatomical connections with other structures. To dissociate these histological effects we used primary cultures and investigated the structure of hippocampal pyramidal neurons in TgCHRNA5/A3/ $B 4$ and their response to nicotine in more controlled conditions. Thy1-EGFP transfected hippocampal primary cultures from WT and TgCHRNA5/A3/B4 embryos were exposed for $48 \mathrm{~h}$ to basal medium (control) or medium with nicotine $(3.25 \mu \mathrm{M})$.

Similar to the adult mouse tissue, the dendritic complexity of cultured hippocampal pyramidal neurons from transgenic embryos was significantly reduced compared to WT cultures ( $p=0.004$, Figure $4 \mathrm{a}-\mathrm{b}$, Sholl analysis). In transgenic pyramidal neurons, we also detected increased density of immature filopodia-like structures compared to WT neurons $(p=0.007)$, while no significant changes were detected in other spines subtypes (Table 2) or the density of total dendritic spines (Figure $4 \mathrm{c}-\mathrm{d}$ ). Cultures from transgenic embryos also presented a significant reduction in GABAergic inputs (VGAT puncta) $(p=0.025$, Figure $4 \mathrm{f})$, but no changes in glutamatergic input (VGLUT1 puncta) (Figure 4e), confirming that overexpression of the CHRN $A 5 / A 3 / B 4$ cluster causes a significant decrease of GABAergic input.

Again, nicotine differentially affected the dendritic complexity and presynaptic inputs depending on the genotype. Sholl analysis revealed that while nicotine was able to restore the dendritic complexity in transgenic neurons $(p=0.002)$, the same treatment caused detrimental effects on WT cultures reducing the dendritic arborization $(p=0.009$, Figure $4 \mathrm{a}-\mathrm{b}$, Sholl analysis). Nicotine exposure did not modify the density of glutamatergic inputs neither in WT or transgenic cultures (Figure $4 \mathrm{e})$, but reduced stubby spines $(p=0.033)$, without affecting filopodia and mushroom-like spines (Table 2) or the total spine density (Figure 4c-d). However, nicotine reduced VGAT puncta in control cultures $(p=0.025)$, while it had no effect in transgenic cultures (Figure 4f). The MTT control assay revealed no significant differences among groups (WT control $1.00 \pm 0.00$; WT nicotine $0.84 \pm 0.123 ; \mathrm{TgC} H R N A 5 / A 3 /$ $B 4$ control $1.39 \pm 0.297$; $\operatorname{TgCHRNA5/A3/B4}$ nicotine $1.24 \pm 0.251$ ), indicating that the viability of the culture was not affected by the nicotine exposure. 

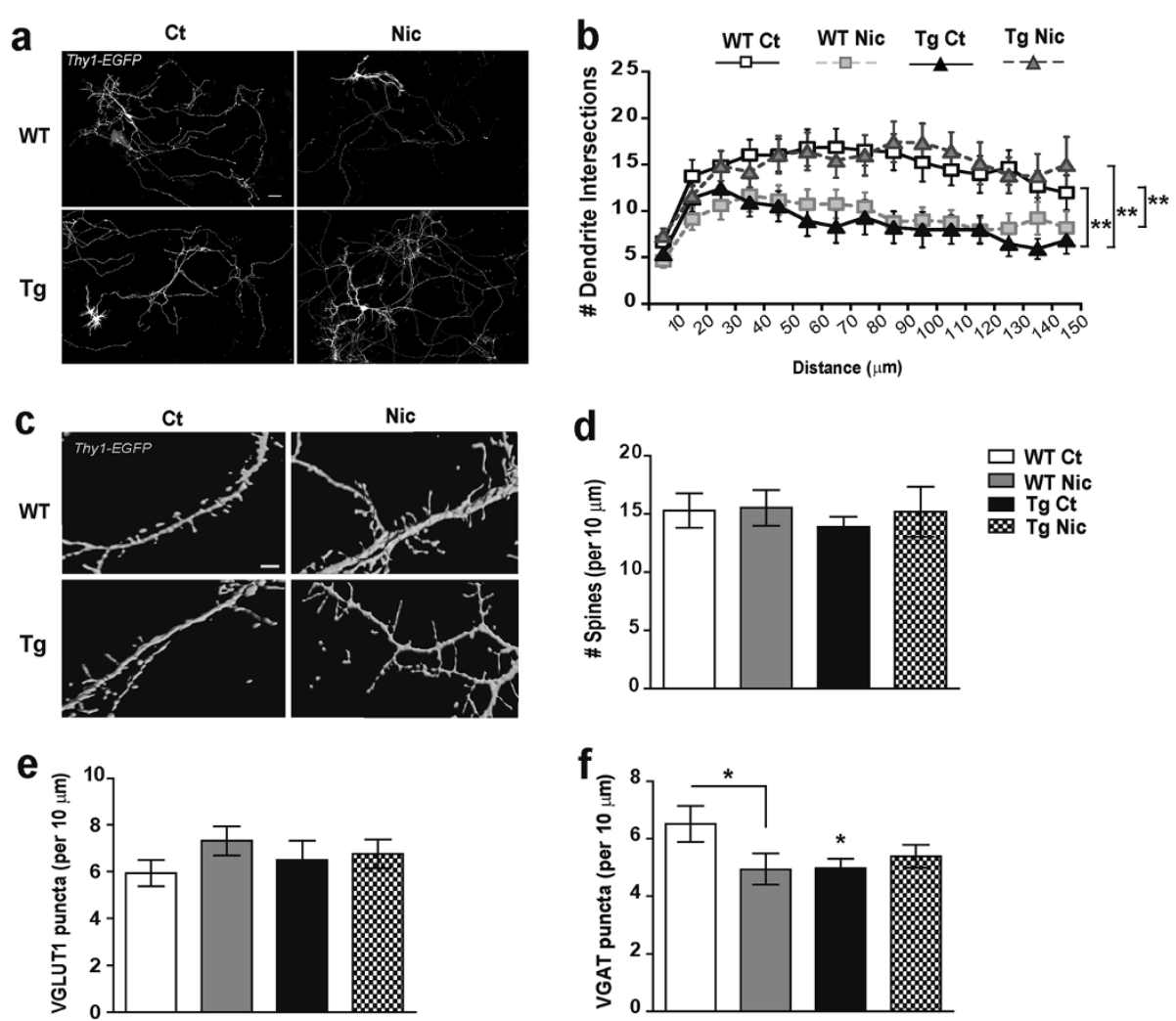

Figure 4 Pyramidal neurons structure in hippocampal primary cultures. (a) Photomicrograph illustrating positive Thy 1-Enhanced Green Fluorescent Protein (EGFP) pyramidal neurons from wild type (WT) and TgCHRNA5/A3/B4 (Tg) cultures exposed to medium alone (Control, Ct) or containing nicotine (Nic, $3.25 \mu \mathrm{M}$ ) for $48 \mathrm{~h}$, Scale bar $25 \mu \mathrm{m}$. (b) Sholl analysis revealed reduced number dendritic complexity in neurons from Tg cultures, as compared to WT. Chronic exposure to nicotine rescued the reduced dendritic complexity in Tg cultures. In contrast, in WT cultures the same treatment reduced the dendritic arborisation. (c) Photomicrograph illustrating dendritic spines in EGFP transfected neurons from the experimental conditions indicated, Scale bar $2 \mu \mathrm{m}$. (d) Quantification of spines per $10 \mu \mathrm{m}$ of dendrite length showed no differences among groups. Quantification of the number of (e) VGLUT1 and (f) VGAT puncta per $10 \mu \mathrm{m}$ of dendrite length in cultures from the experimental conditions indicated. No differences in VGLUT1 puncta were detected among groups. Instead, VGAT puncta were reduced in Tg, as compared to WT cultures. Nicotine treatment reduced VGAT inputs only in WT but not in Tg cultures ( $n=4-5$ cells/culture; $3-4$ cultures/condition from $\geq 3$ experiments). ${ }^{*} p \leq 0.05,{ }^{* *} p \leq 0.01$.

Impaired novelty recognition memory in TgCHRNA5/A3/B4 mice is rescued upon chronic nicotine treatment Finally, we examined to what extent $\operatorname{Tg} C H R N A 5 / A 3 / B 4$ presented an altered cognitive performance and if so, what was the effect of the chronic nicotine treatment (Figure 5a). In humans, single nucleotide polymorphisms

Table 2 Effects of nicotine exposure on dendritic spines in pyramidal neurons from hippocampal primary cultures

\begin{tabular}{ccccc}
\hline $\begin{array}{l}\text { Spines } \\
\text { per 10 } \boldsymbol{\mu m}\end{array}$ & Filopodia & Stubby & Mushroom-like & Thin \\
\hline WT Ct & $0.56 \pm 0.15$ & $2.23 \pm 0.72$ & $12.05 \pm 1.44$ & $1.00 \pm 0.24$ \\
WT Nic & $0.93 \pm 0.22$ & $0.94 \pm 0.29^{\omega}$ & $12.82 \pm 1.32$ & $1.75 \pm 0.37$ \\
Tg Ct & $1.61 \pm 0.35^{\sigma}$ & $1.18 \pm 0.34$ & $10.96 \pm 0.86$ & $1.72 \pm 0.31$ \\
Tg Nic & $2.29 \pm 0.68^{\sigma}$ & $0.65 \pm 0.23^{\omega}$ & $12.21 \pm 2.21$ & $2.32 \pm 0.44$ \\
\hline
\end{tabular}

Number of spines per $10 \mu \mathrm{m}$ of dendrite length, in neurons from wild type (WT) and TgCHRNA5/A3/B4 (Tg) embryos. Cultures were incubated with medium alone ( $\mathrm{Ct}$, Control) or containing nicotine (Nic, $3.25 \mu \mathrm{M})$ for $48 \mathrm{~h}$ ( $n=4-5$ cells/culture; $3-4$ cultures/condition from $\geq 3$ experiments). Two-way ANOVA genotype effect $\sigma p \leq 0.05$, treatment effect $\omega p \leq 0.05$. within the $C H R N A 5 / A 3 / B 4$ locus have been associated with reduced performance in cognitive tasks requiring discriminative abilities. In the sense that carriers of the nicotine addiction risk allele present difficulties in working memory and attention and in maintaining and updating information over short delays [27]. In rodents, the hippocampus plays a significant role in discrimination memory [54], while intra-hippocampus infusion of nAChRs agonists facilitate recognition memory [55]. We found that saline-treated $\operatorname{TgCHRNA5/A3/B4}$ mice exhibited impaired short-term novelty recognition memory, as compared to WT. During the test session of the novel object recognition paradigm, they showed a similar exploration rate towards the familiar and novel objects as compared to WT (Additional file 3: Figure $\mathrm{S} 3 \mathrm{a})$. As a consequence, the discrimination index was significantly reduced in $\operatorname{TgCHRNA5/A3/B4}$ mice, compared to saline-treated WT littermates ( $p=0.008$, Figure $5 \mathrm{c}$ ). During this recognition session, no differences were 
a

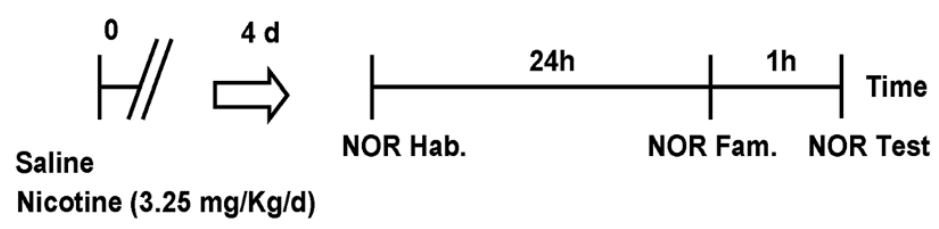

b

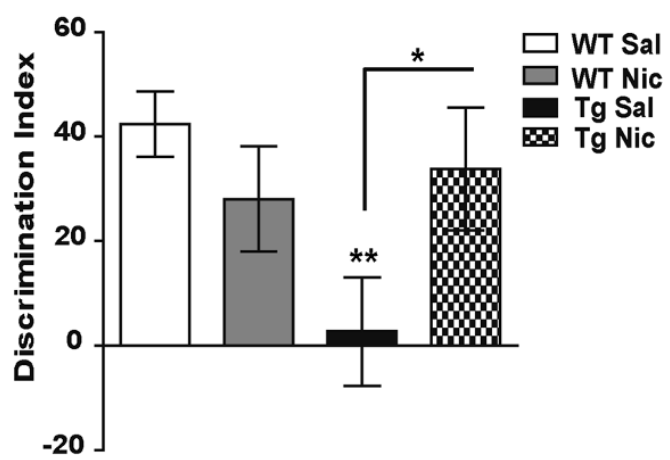

Figure $\mathbf{5}$ Short-term novel object recognition memory. (a) Drug administration protocol used during the novel object recognition (NOR) task (Hab, Habituation session; Fam, Familiarization session; Test session). (b) Saline (Sal)-treated TgCHRNA5/A3/B4 (Tg) mice presented a significant impairment in recognition memory, as compared to wild type (WT) littermates, as shown by reduced discrimination index which was expressed as [(time exploring the novel object - time exploring the familiar object)/total time of exploration*100]. Chronic administration of nicotine (Nic, $3.25 \mathrm{mg} / \mathrm{kg} / \mathrm{d}$ ) for $5 \mathrm{~d}$ rescued the impaired recognition memory in Tg mice, but had no effect in WT ( $\mathrm{n}=10-12$ animals/group from $\geq 3$ experiments). ${ }^{*} p \leq 0.05,{ }^{* *} p \leq 0.01$.

detected between genotypes in total exploration rates or anxiety-like behavior (Additional file 3: Figure S3b-c).

Chronic nicotine did not affect novelty recognition memory in WT animals, but it completely reversed the impaired short-term novel object recognition memory in salinetreated $\operatorname{Tg} C H R N A 5 / A 3 / B 4$ mice $(p=0.035$, Figure $5 c)$. The treatment reduced the time that transgenic mice spent exploring the familiar object, while increased the exploration time for the novel object (Additional file 3: Figure S3a). Both WT and TgCHRNA5/A3/B4 receiving the drug showed similar amounts of exploration and anxiety-like behavior, as compared to saline-treated mice (Additional file 3: Figure S3b-c).

\section{Discussion}

The present study demonstrates that the CHRNA5/A3/ $B 4$ gene cluster contributes to defining the dendritic complexity of hippocampal pyramidal neurons, the excitatory and inhibitory inputs in the hippocampus and novelty recognition memory. Moreover, deregulation of this genomic region modifies the effects of a chronic nicotine treatment on hippocampal neuroplasticity and cognitive function.

Overexpression of the CHRNA5/A3/B4 cluster in mice leads to a significant reduction in the dendritic arborization of CA1 pyramidal neurons. Morphological reconstructions using Lucifer Yellow injections and genetically driven Thy-
YFP expression in mice revealed that pyramidal neurons of $\operatorname{TgCHRNA5/A3/B4}$ show a reduced total dendritic tree length, volume and branching, resulting in decreased target space. Our morphological analysis also revealed a higher proportion of stubby spines on both apical and basal dendrites in transgenic pyramidal neurons. Stubby spines are considered immature forms of spines in the adult brain [56] and an increased proportion in $\operatorname{TgCHRNA5/A3/B4}$ support the view that overexpression of the CHRNA5/A3/ $B 4$ cluster impairs spine maturation. Moreover, immunostaining results for the presynaptic marker VGLUT1 showed that excitatory synaptic inputs in CA1 strata radiatum and oriens in $\operatorname{TgCHRNA5/A3/B4}$ are reduced. Spines lacking synaptic inputs are thought to be less stable in time [57], and thus may explain the increased immature spines in $\operatorname{TgCHRNA5/A3/B4}$. Intriguingly, our results resemble those observed in CA1 pyramidal neurons of mice lacking the $\alpha 7 \mathrm{nAChR}$ subunit ( $\alpha 7 \mathrm{KOs}$ ) that show reduced dendritic complexity along with increased dendritic spine density [58]. However, although $\alpha 7 \mathrm{KOs}$ lack glutamatergic synapses in the CA1 region, they show no changes in GABAergic synapses [51]. This contrasts our data, since $\operatorname{TgCHRNA5/A3/B4}$ show reduced inhibitory inputs in CA1 strata radiatum and oriens along with an increased ratio of glutamatergic/GABAergic inputs. Loss of inhibition and hippocampal hyper-excitability has been associated with reduced growth of dendritic arbors [59], and delayed maturation and stability of dendritic 
spines [16,17]. Noteworthy, the phenotype of TgCHRNA5/ $A 3 / B 4$ cannot be attributed to reduced $\alpha 7-n A C h R s$ since our previous studies showed normal levels of $\alpha 7$-nAChRs on the hippocampus [38]. Interestingly, $\alpha 3 \mathrm{nAChR}$ subunit is increased in the hippocampus of $\alpha 7 \mathrm{KOs}$ [60], thus suggesting that the phenotype of $\alpha 7 \mathrm{KO}$ could be interpreted as a consequence of a $\alpha 3-n A C h R s$ overexpression.

Disrupted dendritic arbor and spines in the CA1 pyramidal neurons usually are assumed to impair synaptic efficacy in this region [61,62]. Nevertheless, electrophysiological recordings demonstrated that applying HFS to the SC afferents elicits similar degree of CA1 synaptic potentiation in transgenic hippocampal slices. The PPR is also similar between genotypes, suggesting no change in release probability. In the CA1 region, nAChRs containing the $\alpha 5, \alpha 3$ or $\beta 4$ subunits are mainly found on stratum radiatum interneurons $[30,32]$, where they control pyramidal cell soma and apical dendritic tree excitability. Nevertheless, they are also expressed by pyramidal neurons [33]. nAChRs play a significant role in the expression of LTP in the CA1 $[7,63]$ and it may be possible that increased nAChRs in CA1 region of $\operatorname{TgCHRNA5/A3/B4}$ [37] contribute to synaptic efficacy in SC-CA1 connections, overcoming the detrimental structure of CA1 pyramidal neurons.

Because in our transgenic model the overexpression of the cluster $C H R N A 5 / A 3 / B 4$ occurs since fertilization [37], the overall structural and network connectivity alterations detected in $\operatorname{TgCHRNA5/A3/B4}$ could arise from early development. Our studies in cultured hippocampal neurons support this idea since transgenic neurons develop with a less complex dendritic tree, higher proportions of immature filopodia-like structures and also deficits in GABAergic inputs. Recent observations have shown an important role of $\alpha 5$-nAChRs during development. Thus, mice lacking the $\alpha 5$ subunit ( $\alpha 5 \mathrm{KOs}$ ) lose a dendritic pruning of apical dendrites in developing cortical pyramidal neurons [64]. This would suggest that the reduced dendritic branching in TgCHRNA5/A3/B4 could be the result of excessive pruning driven by $\alpha 5$ nAChRs. The loss of pruning in $\alpha 5 \mathrm{KOs}$ has been associated with attentional deficits in these mutant mice $[64,65]$. We found impaired short-term recognition memory in our $\operatorname{TgCHRNA5/A3/B4}$ that may also be related with this cognitive role of $\alpha 5$-nAChRs. In humans, genetic variations within the CHRNA5/A3/B4 cluster are associated with lower discriminative abilities and with an increase in the levels of nAChRs expression [27]. In rodents, the novel object recognition paradigm is the best suited to study discriminative abilities. Performance in the novel object recognition test depends on the hippocampus and the perirhinal cortex, and in fact, the activation of nAChRs in both regions facilitates recognition memory [55]. Moreover, the same genetic variations have also been associated with decreased functional connectivity strength in cortical and subcortical circuits, including the hippocampus, shown by functional magnetic resonance imaging studies [66]. Thus, it may be conceivable that CHRNA5/ $A 3 / B 4$ overexpression induces alterations in the perirhinal cortex, but this is less probable due to the low levels of expression of the $\alpha 3, \alpha 5$ and $\beta 4$ nAChRs subunits in this region $[67,68]$.

Next we investigated how the CHRNA5/A3/B4 region influences the effects of nicotine on hippocampal plasticity. Our findings demonstrate that chronic nicotine exposure differentially shapes the dendritic tree of CA1 pyramidal neurons in TgCHRNA5/A3/B4 and WT mice. In WT mice, chronic nicotine treatment significantly reduces the number of basal and apical dendrites. Previous studies have observed similar effects on hippocampal morphology but upon developmental exposure to nicotine [69,70]. Remarkably, the effects of nicotine are opposite in $\mathrm{TgCHR}$ $N A 5 / A 3 / B 4$, in which nicotine increases arborization completely rescuing the reduced dendritic complexity. Similar to our results, in $\alpha 5 \mathrm{KOs}$, nicotine treatment also compensates their pruning defect and abnormal increase of dendritic branching in developing cortical neurons, while the same treatment causes opposite effects in control animals [71]. This suggests that $\alpha 5-n A C h R s$ may contribute to the differential response to nicotine observed in TgCHRNA5/ $A 3 / B 4$. Recent studies have demonstrated that genetic factors define different effects of cocaine in modifying the dendritic arbor of CA1 pyramidal neurons. Drug-induced plasticity in dendritic complexity is higher in rats prone to development of drug addiction [72]. Both TgCHRNA5/ $A 3 / B 4$ and $\alpha 5 \mathrm{KO}$ mice show increased nicotine selfadministration, as compared to control mice [37,73,74]. Whether the differential response to nicotine on dendritic arborization could be linked to development of nicotine addiction requires further investigation.

We also found that chronic exposure to nicotine increases the density of mushroom-like spines in apical dendrites of CA1 pyramidal neurons in both genotypes and compensates for the reduced proportion of stubby versus mushroom-like spines in TgCHRNA5/A3/B4. However, immunostaining experiments showed that chronic nicotine treatment induces differential genotype effects on presynaptic excitatory and inhibitory inputs. In WT mice, nicotine reduces both VGAT and VGLUT1 presynaptic inputs but does not affect the E/I balance. This is in contradiction with previous work reporting that nicotine increases only glutamatergic synapses in the CA1 region, without changing GABAergic synapses [51]. Differences in the dose of nicotine used, duration of the treatment and the age of animals could explain these discrepancies. Conversely, in $\operatorname{TgCHRNA5/A3/B4}$ mice, chronic nicotine normalizes the reduced glutamatergic and GABAergic presynaptic inputs and restores the $\mathrm{E} / \mathrm{I}$ imbalance. The experiments in primary cell cultures confirmed that overexpression of CHRNA5/ 
$A 3 / B 4$ alters the effects of nicotine on dendrite branching and presynaptic VGAT puncta. A differential response to GABA in TgCHRNA5/A3/B4 mice may require further investigation, given the important role of GABA during the development of nicotine addiction [75].

The electrophysiological recordings revealed that chronic nicotine treatment facilitates LTP induction at SC-CA1 pathway, in agreement with previous published data [76-78]. Nevertheless, this effect was similar in both genotypes. Since nicotine enhances LTP responses via nAChRs containing the $\beta 2$ subunit [79], it seems likely that this response to nicotine is not altered in our $\operatorname{TgCHRNA5/A3/B4}$.

According to other authors [80], we found that chronic nicotine treatment has no impact on recognition memory in WT animals. Interestingly, the same treatment restores the impairment in recognition memory in TgCHRNA5/ $A 3 / B 4$ mice, similar to what has been described in humans with genetic mutations in this cluster [28].

In summary, in this study we provide new evidence that the overexpression of the CHRNA5/A3/B4 region disrupts pyramidal neuronal structure in the hippocampus, and thus affecting the cognitive capacities. The present work also demonstrates that $C H R N A 5 / A 3 / B 4$ overexpression modifies nicotine-induced changes on dendritic architecture, presynaptic excitatory/inhibitory inputs and recognition memory, but not on synaptic potentiation. Understanding how the CHRNA5/A3/B4 locus drives the effects of nicotine may help to develop new therapeutic strategies for the pathogenesis of tobacco addiction.

\section{Additional files}

Additional file 1: Figure S1. Morphological analysis of the dendritic tree in Lucifer Yellow transfected CA1 pyramidal neurons. The apical dendritic tree of TgCHRNA5/A3/B4 (Tg) showed reduced total number of dendrite nodes (a), length (b) and volume (c), as compared to wild type (WT) mice ( $n=5-10$ cells/animal; $4-5$ animals/group from $\geq 3$ experiments). ${ }^{*} p \leq 0.05,{ }^{* * *} p \leq 0.001$.

Additional file 2: Figure S2. Number of pyramidal somas per area in the CA1 and CA3 layers. Thy1-yellow fluorescent protein (YFP)-wild type (WT) and Thy1-YFP-TgCHRNA5/A3/B4 (Tg) mice that received either saline (Sal) or nicotine (Nic, $3.25 \mathrm{mg} / \mathrm{Kg} / \mathrm{d}$ ) for $7 \mathrm{~d}$ showed similar number of pyramidal cell somas per area in stratum pyramidale (SP) CA1 and CA3 layers ( $n=\geq 100$ images animal; 4-5 animals/group from $\geq 3$ experiments).

Additional file 3: Figure S3. Novel object recognition test session. $\operatorname{TgCHRNA5/A3/B4}(\mathrm{Tg})$ mice spent similar amount of time (s) exploring the familiar and novel objects, as compared to their wild type (WT) littermates. Chronic administration of nicotine (Nic, $3.25 \mathrm{mg} / \mathrm{Kg} / \mathrm{d}$ ) for $5 \mathrm{~d}$ increased the time that $\mathrm{Tg}$ spent exploring the novel object while reduced the time exploring the familiar object, in comparison to Tg that received saline (Sal) (a). No differences were observed among the four groups of animals in total time of exploration (b) and, time spent in the periphery and centre of the open field (\%) (c) along the 5 min duration session ( $n=10-12$ animals/group from $\geq 3$ experiments).

\section{Competing interests}

The authors declare that they have no competing interests.

\section{Acknowledgements}

The laboratory of Mara Dierssen is supported by Departament d'Universitats, Recerca i Societat de la Informació (Grups consolidats 09 2009SGR1313). This work was supported by Grants SAF2010-16427, SAF2007-31093-E, and FIS (PI 082038); Marató TV3; the Jerome Lejeune, Koplowitz, FRAXA and Areces Foundations; and the European Union (CureFXS ERare-EU/FIS PS09102673, EU- Era NET Neuron. FOOD for THOUGHT F4T). The laboratory of Mairena Martín is supported by Ministerio de Economía y Competitividad (BFU201123034). The Centro de Investigación Biomédica en Red de Enfermedades Raras is an initiative of the Instituto de Salud Carlos III. The laboratory of María V. Sánchez is supported by Ministerio de Economía y Competitividad (BFU2011-27094).

We would like to thank Francesc Xavier Gallego and Mónica Joana Pinto do Santos for their assistance with the behavioral tests and their valuable critical reading of the manuscript.

\section{Author details}

${ }^{1}$ Cellular and Systems Neurobiology, Systems Biology Program, Centre for Genomic Regulation (CRG), Barcelona Biomedical Research Park (PRBB) building, Room 522.04; C/ Dr. Aiguader 88, E-08003 Barcelona, Spain. ${ }^{2}$ Universitat Pompeu Fabra (UPF), E-08003 Barcelona, Spain. ${ }^{3}$ Centro de Investigación Biomédica en Red de Enfermedades Raras (CIBERER), E-08003 Barcelona, Spain. ${ }^{4}$ Department of Inorganic, Organic Chemistry and Biochemistry, Faculty of Medicine, Centro Regional de Investigaciones Biomédicas (CRIB), University of Castilla la Mancha, E-13071 Ciudad Real, Spain. ${ }^{5}$ Department of Inorganic, Organic Chemistry and Biochemistry, Faculty of Chemical Sciences and Techonologies, CRIB, University of Castilla la Mancha, E-13071 Ciudad Real, Spain. ${ }^{6}$ Institut d'Investigacions Biomèdiques August Pi i Sunyer (IDIBAPS), E-08036 Barcelona, Spain. I'Institució Catalana de Recerca i Estudis Avançats (ICREA), E-08010 Barcelona, Spain.

Received: 15 September 2014 Accepted: 2 October 2014

Published online: 11 November 2014

\section{References}

1. Hyman SE (2005) Addiction: a disease of learning and memory. Am J Psychiatry 162(8):1414-1422

2. Koob GF, Le Moal M (2005) Plasticity of reward neurocircuitry and the 'dark side' of drug addiction. Nat Neurosci 8(11):1442-1444

3. Robinson TE, Kolb B (2004) Structural plasticity associated with exposure to drugs of abuse. Neuropharmacology 47(Suppl 1):33-46

4. Mansvelder HD, McGehee DS (2002) Cellular and synaptic mechanisms of nicotine addiction. J Neurobiol 53(4):606-617

5. Gould TJ (2006) Nicotine and hippocampus-dependent learning: implications for addiction. Mol Neurobiol 34(2):93-107

6. Benowitz NL (2010) Nicotine addiction. N Engl J Med 362(24):2295-2303

7. Yakel $J L$ (2012) Nicotinic ACh receptors in the hippocampus: role in excitability and plasticity. Nicotine Tob Res 14(11):1249-1257

8. Feduccia AA, Chatterjee S, Bartlett SE (2013) Neuronal nicotinic acetylcholine receptors: neuroplastic changes underlying alcohol and nicotine addictions. Front Mol Neurosci 5:83

9. Picciotto MR, Corrigall WA (2002) Neuronal systems underlying behaviors related to nicotine addiction: neural circuits and molecular genetics. J Neurosci 22(9):3338-3341

10. Russo SJ, Dietz DM, Dumitriu D, Morrison JH, Malenka RC, Nestler EJ (2010) The addicted synapse: mechanisms of synaptic and structural plasticity in nucleus accumbens. Trends Neurosci 33(6):267-276

11. Picciotto MR, Higley MJ, Mineur YS (2012) Acetylcholine as a neuromodulator: cholinergic signaling shapes nervous system function and behavior. Neuron 76(1):116-129

12. Patterson F, Jepson C, Loughead J, Perkins K, Strasser AA, Siegel S, Frey J, Gur R, Lerman C (2010) Working memory deficits predict short-term smoking resumption following brief abstinence. Drug Alcohol Depend 106(1):61-64

13. Mackowick KM, Barr MS, Wing VC, Rabin RA, Ouellet-Plamondon C, George TP (2014) Neurocognitive endophenotypes in schizophrenia: Modulation by nicotinic receptor systems. Prog Neuropsychopharmacol Biol Psychiatry 52C:79-85

14. Lee CT, Fuemmeler BF, McClernon FJ, Ashley-Koch A, Kollins SH (2013) Nicotinic receptor gene variants interact with attention deficient hyperactive disorder symptoms to predict smoking trajectories from early adolescence to adulthood. Addict Behav 38(11):2683-2689 
15. Okada H, Ouchi Y, Ogawa M, Futatsubashi M, Saito Y, Yoshikawa E, Terada T, Oboshi Y, Tsukada H, Ueki T, Watanabe M, Yamashita T, Magata Y (2013) Alterations in alpha4beta2 nicotinic receptors in cognitive decline in Alzheimer's aetiopathology. Brain 136(Pt 10):3004-3017

16. Penzes P, Buonanno A, Passafaro M, Sala C, Sweet RA (2013) Developmental vulnerability of synapses and circuits associated with neuropsychiatric disorders. J Neurochem 126(2):165-182

17. Penzes P, Cahill ME, Jones KA, VanLeeuwen JE, Woolfrey KM (2011) Dendritic spine pathology in neuropsychiatric disorders. Nat Neurosci 14(3):285-293

18. Koleske AJ (2013) Molecular mechanisms of dendrite stability. Nat Rev Neurosci 14(8):536-550

19. Wang JC, Kapoor M, Goate AM (2012) The genetics of substance dependence. Annu Rev Genomics Hum Genet 13:241-261

20. Ware JJ, van den Bree M, Munafo MR (2012) From men to mice: CHRNA5/ CHRNA3, smoking behavior and disease. Nicotine Tob Res 14(11):1291-1299

21. Herman Al, Sofuoglu M (2010) Cognitive effects of nicotine: genetic moderators. Addict Biol 15(3):250-265

22. Mihailescu S, Drucker-Colin R (2000) Nicotine, brain nicotinic receptors, and neuropsychiatric disorders. Arch Med Res 31(2):131-144

23. Boulter J, Connolly J, Deneris E, Goldman D, Heinemann S, Patrick J (1987) Functional expression of two neuronal nicotinic acetylcholine receptors from cDNA clones identifies a gene family. Proc Natl Acad Sci U S A 84(21):7763-7767

24. Saccone SF, Hinrichs AL, Saccone NL, Chase GA, Konvicka K, Madden PA, Breslau N, Johnson EO, Hatsukami D, Pomerleau O, Swan GE, Goate AM, Rutter J, Bertelsen S, Fox L, Fugman D, Martin NG, Montgomery GW, Wang JC, Ballinger DG, Rice JP, Bierut $\mathrm{L}$ (2007) Cholinergic nicotinic receptor genes implicated in a nicotine dependence association study targeting 348 candidate genes with 3713 SNPs. Hum Mol Genet 16(1):36-49

25. Bierut LJ, Stitzel JA, Wang JC, Hinrichs AL, Grucza RA, Xuei X, Saccone NL, Saccone SF, Bertelsen S, Fox L, Horton WJ, Breslau N, Budde J, Cloninger CR, Dick DM, Foroud T, Hatsukami D, Hesselbrock V, Johnson EO, Kramer J, Kuperman S, Madden PA, Mayo K, Nurnberger J Jr, Pomerleau O, Porjesz B, Reyes O, Schuckit M, Swan G, Tischfield JA et al (2008) Variants in nicotinic receptors and risk for nicotine dependence. Am J Psychiatry 165(9):1163-1171

26. Rigbi A, Kanyas K, Yakir A, Greenbaum L, Pollak Y, Ben-Asher E, Lancet D, Kertzman S, Lerer B (2008) Why do young women smoke? V. Role of direct and interactive effects of nicotinic cholinergic receptor gene variation on neurocognitive function. Genes Brain Behav 7(2):164-172

27. Winterer G, Mittelstrass K, Giegling I, Lamina C, Fehr C, Brenner H, Breitling LP, Nitz B, Raum E, Muller H, Gallinat J, Gal A, Heim K, Prokisch H, Meitinger T, Hartmann AM, Moller HJ, Gieger C, Wichmann HE, Illig T, Dahmen N, Rujescu D (2010) Risk gene variants for nicotine dependence in the CHRNA5-CHRNA3-CHRNB4 cluster are associated with cognitive performance. Am J Med Genet B Neuropsychiatr Genet 153B(8):1448-1458

28. Zhang H, Kranzler HR, Poling J, Gelernter J (2010) Variation in the nicotinic acetylcholine receptor gene cluster CHRNA5-CHRNA3-CHRNB4 and its interaction with recent tobacco use influence cognitive flexibility. Neuropsychopharmacology 35(11):2211-2224

29. Placzek AN, Zhang TA, Dani JA (2009) Nicotinic mechanisms influencing synaptic plasticity in the hippocampus. Acta Pharmacol Sin 30(6):752-760

30. Tang AH, Karson MA, Nagode DA, Mclntosh JM, Uebele VN, Renger JJ, Klugmann M, Milner TA, Alger BE (2012) Nerve terminal nicotinic acetylcholine receptors initiate quantal GABA release from perisomatic interneurons by activating axonal T-type (Cav3) Ca(2) channels and Ca (2) release from stores. J Neurosci 31(38):13546-13561

31. Winzer-Serhan UH, Leslie FM (1997) Codistribution of nicotinic acetylcholine receptor subunit alpha3 and beta4 mRNAs during rat brain development. J Comp Neurol 386(4):540-554

32. Winzer-Serhan UH, Leslie FM (2005) Expression of alpha5 nicotinic acetylcholine receptor subunit mRNA during hippocampal and cortical development. J Comp Neurol 481(1):19-30

33. Alkondon M, Pereira EF, Albuquerque EX (2011) Endogenous activation of nAChRs and NMDA receptors contributes to the excitability of CA1 stratum radiatum interneurons in rat hippocampal slices: effects of kynurenic acid. Biochem Pharmacol 82(8):842-851

34. Albuquerque EX, Pereira EF, Alkondon M, Rogers SW (2009) Mammalian nicotinic acetylcholine receptors: from structure to function. Physiol Rev 89(1):73-120
35. Alkondon M, Pereira EF, Albuquerque EX (1996) Mapping the location of functional nicotinic and gamma-aminobutyric acidA receptors on hippocampal neurons. J Pharmacol Exp Ther 279(3):1491-1506

36. Lin H, Hsu FC, Baumann BH, Coulter DA, Lynch DR (2013) Cortical synaptic NMDA receptor deficits in alpha7 nicotinic acetylcholine receptor gene deletion models: Implications for neuropsychiatric diseases. Neurobiol Dis 63:129-140

37. Gallego X, Molas S, Amador-Arjona A, Marks MJ, Robles N, Murtra P, Armengol L, Fernandez-Montes RD, Gratacos M, Pumarola M, Cabrera R, Maldonado R, Sabria J, Estivill X, Dierssen M (2012) Overexpression of the CHRNA5/A3/B4 genomic cluster in mice increases the sensitivity to nicotine and modifies its reinforcing effects. Amino Acids 43(2):897-909, doi:10.1007/s00726-011-1149-y

38. Gallego X, Ruiz-Medina J, Valverde O, Molas S, Robles N, Sabria J, Crabbe JC, Dierssen M (2012) Transgenic over expression of nicotinic receptor alpha 5, alpha 3, and beta 4 subunit genes reduces ethanol intake in mice. Alcohol 46(3):205-215

39. Benowitz NL, Porchet H, Jacob P 3rd (1989) Nicotine dependence and tolerance in man: pharmacokinetic and pharmacodynamic investigations. Prog Brain Res 79:279-287

40. Castane A, Valjent E, Ledent C, Parmentier M, Maldonado R, Valverde O (2002) Lack of CB1 cannabinoid receptors modifies nicotine behavioural responses, but not nicotine abstinence. Neuropharmacology 43(5):857867

41. Elston GN (2001) Interlaminar differences in the pyramidal cell phenotype in cortical areas $7 \mathrm{~m}$ and STP (the superior temporal polysensory area) of the macaque monkey. Exp Brain Res 138(2):141-152

42. Elston GN, Rosa MG (1997) The occipitoparietal pathway of the macaque monkey: comparison of pyramidal cell morphology in layer III of functionally related cortical visual areas. Cereb Cortex 7(5):432-452

43. Ballesteros-Yanez I, Benavides-Piccione R, Elston GN, Yuste R, DeFelipe J (2006) Density and morphology of dendritic spines in mouse neocortex. Neuroscience 138(2):403-409, doi:10.1016/j.neuroscience.2005.11.038

44. Ballesteros-Yanez I, Benavides-Piccione R, Bourgeois JP, Changeux JP, DeFelipe $J$ (2010) Alterations of cortical pyramidal neurons in mice lacking high-affinity nicotinic receptors. Proc Natl Acad Sci U S A 107(25):11567-11572

45. Bourne JN, Harris KM (2008) Balancing structure and function at hippocampal dendritic spines. Annu Rev Neurosci 31:47-67

46. Santos M, D'Amico D, Spadoni O, Amador-Arjona A, Stork O, Dierssen M (2013) Hippocampal hyperexcitability underlies enhanced fear memories in TgNTRK3, a panic disorder mouse model. J Neurosci 33(38):15259-15271

47. Zucker RS (1989) Short-term synaptic plasticity. Annu Rev Neurosci 12:13-31

48. Dere E, Huston JP, De Souza Silva MA (2007) The pharmacology, neuroanatomy and neurogenetics of one-trial object recognition in rodents. Neurosci Biobehav Rev 31(5):673-704

49. Desmond NL, Scott CA, Jane JA Jr, Levy WB (1994) Ultrastructural identification of entorhinal cortical synapses in CA1 stratum lacunosummoleculare of the rat. Hippocampus 4(5):594-600

50. Fiala JC, Feinberg M, Popov V, Harris KM (1998) Synaptogenesis via dendritic filopodia in developing hippocampal area CA1. J Neurosci 18(21):8900-8911

51. Lozada AF, Wang X, Gounko NV, Massey KA, Duan J, Liu Z, Berg DK (2012) Glutamatergic synapse formation is promoted by alpha7-containing nicotinic acetylcholine receptors. J Neurosci 32(22):7651-7661

52. Takacs VT, Klausberger T, Somogyi P, Freund TF, Gulyas Al (2012) Extrinsic and local glutamatergic inputs of the rat hippocampal CA1 area differentially innervate pyramidal cells and interneurons. Hippocampus 22(6):1379-1391, doi:10.1002/hipo.20974

53. Bliss TV, Collingridge GL (1993) Expression of NMDA receptor-dependent LTP in the hippocampus: bridging the divide. Mol Brain 6:5

54. Winters BD, Saksida LM, Bussey TJ (2008) Object recognition memory: neurobiological mechanisms of encoding, consolidation and retrieval. Neurosci Biobehav Rev 32(5):1055-1070, doi:10.1016/j.neubiorev.2008.04.004

55. Melichercik AM, Elliott KS, Bianchi C, Ernst SM, Winters BD (2012) Nicotinic receptor activation in perirhinal cortex and hippocampus enhances object memory in rats. Neuropharmacology 62(5-6):2096-2105

56. Bourne J, Harris KM (2007) Do thin spines learn to be mushroom spines that remember? Curr Opin Neurobiol 17(3):381-386

57. Lozada AF, Wang X, Gounko NV, Massey KA, Duan J, Liu Z, Berg DK (2012) Induction of dendritic spines by beta2-containing nicotinic receptors. J Neurosci 32(24):8391-8400 
58. Morley BJ, Mervis RF (2013) Dendritic spine alterations in the hippocampus and parietal cortex of alpha7 nicotinic acetylcholine receptor knockout mice. Neuroscience 233:54-63

59. Nishimura M, Owens J, Swann JW (2008) Effects of chronic network hyperexcitability on the growth of hippocampal dendrites. Neurobiol Dis 29(2):267-277, doi:10.1016/j.nbd.2007.08.018

60. Yu WF, Guan ZZ, Nordberg A (2007) Postnatal upregulation of alpha4 and alpha3 nicotinic receptor subunits in the brain of alpha7 nicotinic receptordeficient mice. Neuroscience 146(4):1618-1628

61. Quach T, Massicotte G, Belin MF, Honnorat J, Glasper ER, Devries AC, Jakeman LB, Baudry M, Duchemin AM, Kolattukudy PE (2008) CRMP3 is required for hippocampal CA1 dendritic organization and plasticity. FASEB J 22(2):401-409, doi:10.1096/fj.07-9012com

62. Brigman $J \mathrm{~L}$, Wright $T$, Talani $G$, Prasad-Mulcare $S$, Jinde $S$, Seabold GK, Mathur P, Davis MI, Bock R, Gustin RM, Colbran RJ, Alvarez VA, Nakazawa K, Delpire E, Lovinger DM, Holmes A (2010) Loss of GluN2B-containing NMDA receptors in CA1 hippocampus and cortex impairs long-term depression, reduces dendritic spine density, and disrupts learning. J Neurosci 30(13):4590-4600, doi:10.1523/JNEUROSCI.0640-10.2010

63. Gu Z, Yakel JL (2011) Timing-dependent septal cholinergic induction of dynamic hippocampal synaptic plasticity. Neuron 71(1):155-165

64. Tian MK, Bailey CD, De Biasi M, Picciotto MR, Lambe EK (2012) Plasticity of prefrontal attention circuitry: upregulated muscarinic excitability in response to decreased nicotinic signaling following deletion of alpha5 or beta2 subunits. J Neurosci 31(45):16458-16463

65. Bailey CD, De Biasi M, Fletcher PJ, Lambe EK (2010) The nicotinic acetylcholine receptor alpha5 subunit plays a key role in attention circuitry and accuracy. J Neurosci 30(27):9241-9252

66. Hong LE, Hodgkinson CA, Yang Y, Sampath H, Ross TJ, Buchholz B, Salmeron BJ, Srivastava V, Thaker GK, Goldman D, Stein EA (2010) A genetically modulated, intrinsic cingulate circuit supports human nicotine addiction. Proc Natl Acad Sci U S A 107(30):13509-13514

67. Hsu YW, Tempest L, Quina LA, Wei AD, Zeng H, Turner EE (2013) Medial habenula output circuit mediated by alpha5 nicotinic receptor-expressing GABAergic neurons in the interpeduncular nucleus. J Neurosci 33(46):18022-18035

68. Frahm S, Slimak MA, Ferrarese L, Santos-Torres J, Antolin-Fontes B, Auer S, Filkin S, Pons S, Fontaine JF, Tsetlin V, Maskos U, Ibanez-Tallon I (2011) Aversion to nicotine is regulated by the balanced activity of beta4 and alpha5 nicotinic receptor subunits in the medial habenula. Neuron 70(3):522-535

69. Roy TS, Sabherwal U (1998) Effects of gestational nicotine exposure on hippocampal morphology. Neurotoxicol Teratol 20(4):465-473

70. Roy TS, Seidler FJ, Slotkin TA (2002) Prenatal nicotine exposure evokes alterations of cell structure in hippocampus and somatosensory cortex. J Pharmacol Exp Ther 300(1):124-133

71. Bailey CD, Alves NC, Nashmi R, De Biasi M, Lambe EK (2014) Nicotinic alpha5 subunits drive developmental changes in the activation and morphology of prefrontal cortex layer VI neurons. Biol Psychiatry 71(2):120-128

72. Miguens M, Kastanauskaite A, Coria SM, Selvas A, Ballesteros-Yanez I, Defelipe J, Ambrosio E (2013) The Effects of Cocaine Self-Administration on Dendritic Spine Density in the Rat Hippocampus Are Dependent on Genetic Background. Cereb Cortex [Epub ahead of print]

73. Jackson KJ, Marks MJ, Vann RE, Chen X, Gamage TF, Warner JA, Damaj MI (2010) Role of alpha5 nicotinic acetylcholine receptors in pharmacological and behavioral effects of nicotine in mice. J Pharmacol Exp Ther 334(1):137-146

74. Fowler CD, Lu Q, Johnson PM, Marks MJ, Kenny PJ (2011) Habenular alpha5 nicotinic receptor subunit signalling controls nicotine intake. Nature 471(7340):597-601

75. Zhao-Shea R, Liu L, Pang X, Gardner PD, Tapper AR (2013) Activation of GABAergic neurons in the interpeduncular nucleus triggers physical nicotine withdrawal symptoms. Curr Biol 23(23):2327-2335

76. Fujii S, Jia Y, Yang A, Sumikawa K (2000) Nicotine reverses GABAergic inhibition of long-term potentiation induction in the hippocampal CA1 region. Brain Res 863(1-2):259-265

77. Fujii S, Ji Z, Morita N, Sumikawa K (1999) Acute and chronic nicotine exposure differentially facilitate the induction of LTP. Brain Res 846(1):137-143

78. Yamazaki Y, Jia Y, Hamaue N, Sumikawa K (2005) Nicotine-induced switch in the nicotinic cholinergic mechanisms of facilitation of long-term potentiation induction. Eur J Neurosci 22(4):845-860
79. Nakauchi S, Sumikawa K (2012) Endogenously released ACh and exogenous nicotine differentially facilitate long-term potentiation induction in the hippocampal CA1 region of mice. Eur J Neurosci 35(9):1381-1395

80. Kenney JW, Adoff MD, Wilkinson DS, Gould TJ (2012) The effects of acute, chronic, and withdrawal from chronic nicotine on novel and spatial object recognition in male C57BL/6J mice. Psychopharmacology (Berl) 217(3):353-365

doi:10.1186/s40478-014-0147-1

Cite this article as: Molas et al:: Hippocampal changes produced by overexpression of the human CHRNA5/A3/B4 gene cluster may underlie cognitive deficits rescued by nicotine in transgenic mice. Acta Neuropathologica Communications 2014 2:147.

\section{Submit your next manuscript to BioMed Central and take full advantage of:}

- Convenient online submission

- Thorough peer review

- No space constraints or color figure charges

- Immediate publication on acceptance

- Inclusion in PubMed, CAS, Scopus and Google Scholar

- Research which is freely available for redistribution

Submit your manuscript at www.biomedcentral.com/submit 